\title{
CARTA DEL DIRECTOR
}

El problema penitenciario constituye una preocupación global en la actualidad. Este mundo de poblaciones reclusas, posee diversas formas de ser justificado e interpretado. Se trata de un micro cosmos relativo, aparentemente segregado del cuerpo social, pero inextricablemente ligado al resto de ciudadanos de cada nación. Los desafios inmersos en la administración de cárceles y los imperativos de control de las personas encarceladas, se extienden a los actores sociales, desde aquellos que propugnan para que estos sitios se conviertan en lugares de rehabilitación a otros que conciben la función del castigo como la única posible para lidiar con los comportamientos sociales anormales. El tema también tiene un uso político; mientras se suceden los grandes ciclos de auge delincuencial, los politicos de turno suelen utilizarlo para mostrar posturas muy coincidentes con el estado de ánimo en la opinión pública.

De ahí que sigue teniendo vigencia la discusión acerca de si acaso la prisión no constituirá un sistema sumamente caro, para sociedades con exiguos recursos y en los cuales el hacinamiento pareciera no cesar, contrapuesta con la obligación jurídica, ética, moral y política que los gobiernos tienen de garantizar a las personas privadas de libertad, las condiciones que garanticen el pleno respeto a su dignidad humana y que cumplan con el objetivo resocializador proclamado por el Estado Constitucional de Derecho.

Según datos del Centro Internacional para Estudios Penitenciarios de la Universidad de Essex $(R U)$, tan solo los Estados Unidos de América cuentan con una población de 2,3 millones de reclusos, que representaría un 25\% de los presos en el mundo; y con una tasa de 730 reclusos por cada 100,000 habitantes, con una población total de 311 millones de habitantes. Caso distinto el de China Popular cuya tasa ronda los 121 reclusos por 100,000 habitantes; no obstante su población total llega a más de 1,300 millones de personas. En ambos Estados rige la pena de muerte e incluso en este último se critica la práctica de recuperación de órganos de los ejecutados.

De acuerdo a las estadísticas generales de dicho centro de investigación, los contrastes son muy pronunciados en los países de distintas latitudes; asi mientras las tasas de reclusos son elevadas en los Estados de la ex Unión Soviética; como los casos de Georgia con 473 por 100,000 habitantes o Bielorrusia con 438 por 100,000 habitantes las prisiones no son suficientes, asimismo Rusia con más de 1,000 prisiones de distintos niveles de seguridad para una población reclusa que alcanza las 700,000 personas, la tercera del mundo y situando su tasa en 490 por 100,000 habitantes.

Por su parte otros países tienen serios problemas de hacinamiento como Ruanda. Que ocupa un quinto lugar en el mundo con una tasa de 510 reclusos por cada 100,000 habitantes y en donde desde 1994 se registra alta segmentación étnica en las prisiones. En México las prisiones se encuentran al $124 \%$ de su capacidad, en Kenia a 236\% Venezuela a 270\%. Sin embargo las cifras anteriores solo muestran una de las muchas aristas problemáticas inmersas en el tema de cárceles y reclusos.

En El Salvador, según los datos de la Dirección General de Centros Penales (DGCP), al 31 de agosto de este año, habian 26,671 personas encarceladas, a las que se deben sumarse aproximadamente 3,000 detenidos en bartolinas de la PNC y aproximadamente 1,000 menores internos, con lo cual la población a esa fecha sería 30,671, equivalente a una tasa de 511 reclusos por cada 100,000 habitantes, tomando como base una población de 6 millones de habitantes. Además el porcentaje de sobrepoblación, según la DGCP, a la fecha indicada, es de $314 \%$.

A estos datos se suman dificultades para la inversión pública en infraestructura, rezagos en la introducción de la tecnología moderna de control y vigilancia, y peor aún falta de profesionalización del sector penitenciario, lo que conduce inevitablemente a la corrupción y la infiltración del crimen entre los operarios de las prisiones, reforzando a su vez los "poderes fácticos internos" que mediante sus códigos y arreglos imponen un régimen que se desplaza hacia afuera afectando a la ciudadanía en su conjunto, por la fuerza que ejercen algunos delitos como la extorsión. 
Es de hacer notar que en el caso de las Américas, se advierte un incremento de las poblaciones reclusas en ambos géneros. Según datos del Centre for Prisons Studies del King's College de Londres (RU) y publicados en un anuario de una universidad chilena, la tendencia al incremento de privados de libertad se advierte notablemente en los últimos años. Para muestra algunos ejemplos: En Brasil se registraba el mayor segmento de reclusos en ambos géneros en el año 2005; más de 351,000 de hombres y 20,005 de mujeres; mismos que en 2011 alcanzaban los 477,322 y 34,963 respectivamente. Por su parte Colombia pasó de 59,386 (hombres) y 3,727 (mujeres) en 2005 a 86,698 (hombres) y 6,689 (mujeres) en 2011. La tendencia no es diferente para otros países como México y Chile, cuya población reclusa total en el caso del primero en 2005 ascendió a 203,686 (ambos géneros incluidos), elevándose posteriormente en 2011 a 225,697 (total); mientras en Chile de 41,692 reclusos en 2005 se pasaba a 53,602 en 2011.

El desafio de gobernarlos requiere de muchas cosas, desde la necesidad de reducir el porcentaje de privados de libertad sin condena a otros como la cantidad de personal de seguridad que se requiere para un efectivo control de estos segmentos de población. En el primer aspecto, mientras el porcentaje de reclusos sin condena disminuían en algunos países como El Salvador con un $29 \%$ en 2011, muy lejos de su máximo histórico de 83\% del periodo 1978-1982; así también Nicaragua con un 24\% en (2011); Chile pasó de un 52\% (1978-1982) a un 20\% en (2011). Otros paradójicamente aumentaron este porcentaje; tales como Brasil desde un 36\% en 1999 pasó a un 44\% en 2011; por su parte otros países como los centroamericanos se han mantenido estables, aunque constituyen porcentajes altos, por ejemplo Guatemala con un máximo de $58 \%$ en el periodo (2000-2002) a un 53\% en 2011; Honduras con un $88 \%$ en 1999 a un $51 \%$ en 2011. Nótese que las poblaciones reclusas siempre tienden a incrementarse.

Si nos aproximamos al plano de la proporción de guardias de seguridad por el total de población reclusa, se encontrarán algunas brechas importantes. Mientras que en Brasil para 2011, existían 69,843 guardias con una proporción de 7,3 personas presas por guardia de seguridad, un diferencial más alto se registraba en otros países como Colombia con una proporción de 8,2 presos por guardias; de un total de 11,461 miembros del personal de seguridad; o las de Honduras y Nicaragua con proporciones de 9,5 y 9,2 respectivamente sobre la base de segmentos de guardias de seguridad de 832 y 1,301 para el año 2011. En El Salvador para la misma fecha el diferencial era de 17,3 presos por guardias cuyo conjunto se cifraba en 1,407.

En El Salvador, de acuerdo a datos de la Dirección General de Centros Penales, para agosto de 2013 se registraba una población reclusa de alrededor de 27,000; distribuidos en 19 centros penitenciarios, 3 centros de resguardo y un centro abierto que en su conjunto tienen una capacidad instalada para 8,090 reclusos, la diferencia es de 18,910. Los condenados alcanzaban los 20,019 $y$ los procesados 6,861. El centro penal más poblado es la Esperanza con 5,231 reclusos sobre una capacidad instalada para 800 presos; mientras los menos poblados son el de Zacatecoluca con 329 y el de Metapán con 273. Las tasas de hacinamiento son significativas y por ello los imperativos deben dirigirse a politicas penitenciarias integrales que impacten decisivamente en el sector carcelario. Los problemas sin embargo no se reducen a eso, por ello valdría la pena, recuperar a manera de hoja de ruta las recomendaciones que en su momento hizo el Programa de las Naciones Unidas para el Desarrollo (PNUD) en el año 2000 en un estudio intitulado "Acceso a la Justicia en Centroamérica y Panamá Población Privada de Libertad", el cual se referían a aspectos tan vitales como la información confiable, vinculaciones sociales con las prisiones, alternativas a la prisión, infraestructura y otros.

Jaime Edwin Martinez Ventura

Director General Academia Nacional de Seguridad Pública

Septiembre 3 de 2013 